classes (Ellsworth, 1991). While researchers in schizophrenia have tended to emphasise cognitive dysfunction over emotional dysregulation in schizophrenia, a more fruitful approach might take the cognitive and affective symptoms of schizophrenia as evidence of unifying neurobiological processes which link emotion and cognition. In our research effort, we try to characterise the neural structures and molecular markers which carry out these processes, which should bring about a greater understanding of what it means to say that emotions and cognition interact with each other, in normal and pathological conditions.

Ellsworth, P. C. (1991) Some implications of cognitive appraisal theories of emotion. In internotional Review of Studies on Emotion, Vol I (ed. K. T. Strongman), pp. 143-161. New York: John Wiley and Sons.

Taylor, S. F. \& Lberzon, I. (1999) Paying attention to emotion in schizophrenia. British fournal of Psychiotry. 174, 6-8.

S. F. Taylor, I. Liberzon Department of Psychiatry, University of Michigan Medical Center, UH 9D Box 0118, 1500 East Medical Center Drive, Ann Arbor, MI 48109-0118, USA

\section{Family burden of caring for people with mental illness}

Sir: Jenkins \& Schumacher (1999) commented on the universality of burden in caring for people with mental illness, and the sociocultural factors that might influence it.

We have had the opportunity of studying family burden in a number of different psychiatric illnesses including schizophrenia, affective disorders, and 'neurotic' conditions such as generalised anxiety disorder, dysthymia, and obsessive-compulsive disorder (Chakrabarti et al, 1992, 1993, 1995, 1996). Most of our families had problems in caring for their mentally ill relative, with over $90 \%$ of families, across different patient groups, experiencing moderate to severe burden. However, mean scores of burden were greatest among families of patients with schizophrenia, followed by bipolar disorder, major depression and 'neurotic' disorders. Subjective reports of burden were proportionately less, reflecting a high degree of tolerance on the part of relatives. On examining the influence of various factors on burden we found that the strongest predictors of the extent or severity of burden were a longer duration of illness and higher levels of disability. Socio-demographic parameters such as age, gender, marital status, income or residence had a lesser and more inconsistent influence on the severity of burden. These seemed to be more important in determining the pattern or distribution of burden in various areas, such as finances, disruption of family routine, or interactions.
Our results emphasise the need for a distinction between the extent (severity/ quantity) of burden, and its pattern (typology/quality). The former seems to be more influenced by clinical factors such as duration, disability, type and severity of illness, whereas the latter is more likely to be determined by social and cultural factors. We agree with Jenkins \& Schumacher that it is the quality of burden which merits further investigation, because it can offer useful insights into how mental illness affects families across different social, cultural and ethnic groups.

Chakrabarti, S., Kulhara, P. \&erma, S. K. (1992) Extent and determinants of burden among families of patients with affective disorders. Acto Psychiotrico Scondinovico. 86, 247-252.

_, _ _ (1993) The pattern of burden in families of neurotic patients. Social Psychiotry and Psychiotric Epidemiology, 28, 172-177.

_, Raj, L., Kulhara, P., et ol (1995) Comparison of the extent and pattern of family burden in affective disorders and schizophrenia. Indian journol of Psychiotry. 37, $105-112$.

—, Kulhara, P. \&erma, S. K. (19\%6) Family burden of neurosis; extent and determinants. Hong Kong Journal of Psychiotry, 6. 23-28.

Jenkims, J. H. \& Schumacher, J. C. (1999) Family burden of schizophrenia and depressive illness. Specifying the effects of ethnicity, gender and social ecology. British journal of Psychiatry, 174, 31-38.

S. Chakrabarti, P. Kulhara Department of Psychiatry, Postgraduate Institute of Medical Education \& Research, Chandigarh-160012, India

\section{One hundred years ago}

\section{From: Medico-legal notes}

"The important classification to be made among the insane so far as society is concerned, is a division into dangerous and non-dangerous insane." The various procedures followed in permitting the release of such of the criminal insane as have presumably recovered are detailed at length. It is self-evident that this is a matter in which the utmost care should be exercised. "The importance of a combination of judicial, administrative, and medical authority in authorizing the discharge of a prisoner as laid down by the Paris Congress cannot be doubted." In Georgia in the case of a capital crime committed by a lunatic, the patient cannot be released from the hospital except by a special act of the legislature. "In the French discussions, great importance is justly placed on the necessity of carefully guarding society from the dangers incident to a too easy discharge of the criminal insane. It was suggested that the principle of conditional liberation might well be applied to insane criminals. It is practiced at Broadmoor, England, with excellent results. A person who, after being carefully observed for a sufficient length of time, seems to be cured, is committed to relatives who under- take to guard him, but the State reserves the right to effective control. The patient is subjected to frequent visits and in case of the violation of the rules imposed, whether on the part of the patient or his guardian, is recommitted to Broadmoor. The method seems to offer all the necessary guarantees for the protection of society."

\section{REFERENCE}

Americon journal of insonity, April 1899, 744.

Researched by Henry Rollin, Emeritus Consultant Psychiatrist, Horton Hospital, Epsom, Surrey 